\title{
Forcing variables in simulation of transpiration of water stressed plants determined by principal component analysis**
}

\author{
Angelica Durigon ${ }^{*}$, Quirijn de Jong van Lier ${ }^{2}$, and Klaas Metselaar ${ }^{3}$ \\ ${ }^{1}$ Department of Crop Science, Agricultural Meteorology Group, Federal University of Santa Maria, \\ Av. Roraima, 1000, building 77, 97105-900, Santa Maria (RS), Brazil \\ ${ }^{2}$ Soil Physics Laboratory, Centre for Nuclear Energy in Agriculture, University of São Paulo, \\ P.O. Box 96, 13405-900, Piracicaba (SP), Brazil \\ ${ }^{3}$ Soil Physics and Land Management Group, Department of Environmental Science, Wageningen University and Research Centre,
} P.O. Box 47, 6700 AA, Wageningen, The Netherlands

Received August 31, 2015; accepted July 12, 2016

\begin{abstract}
A b s t r a c t. To date, measuring plant transpiration at canopy scale is laborious and its estimation by numerical modelling can be used to assess high time frequency data. When using the model by Jacobs (1994) to simulate transpiration of water stressed plants it needs to be reparametrized. We compare the importance of model variables affecting simulated transpiration of water stressed plants. A systematic literature review was performed to recover existing parameterizations to be tested in the model. Data from a field experiment with common bean under full and deficit irrigation were used to correlate estimations to forcing variables applying principal component analysis. New parameterizations resulted in a moderate reduction of prediction errors and in an increase in model performance. $A g_{s}$ model was sensitive to changes in the mesophyll conductance and leaf angle distribution parameterizations, allowing model improvement. Simulated transpiration could be separated in temporal components. Daily, afternoon depression and long-term components for the fully irrigated treatment were more related to atmospheric forcing variables (specific humidity deficit between stomata and air, relative air humidity and canopy temperature). Daily and afternoon depression components for the deficit-irrigated treatment were related to both atmospheric and soil dryness, and long-term component was related to soil dryness.
\end{abstract}

K e y w o r d s: $A g_{\mathrm{s}}$ model, net $\mathrm{CO}_{2}$ assimilation rate, stomatal conductance, common bean

\section{INTRODUCTION}

Measuring plant transpiration rate at canopy scale is laborious and results are often uncertain. Modern techniques to measure plant transpiration include porometers

\footnotetext{
*Corresponding author e-mail: angelica.durigon@gmail.com

**The work was financial supported by the São Paulo Research

Foundation -FAPESP (projects 2012/09316-8 and 2013/19374-8).
}

(Ansley et al., 1994; Silva et al., 2016), gas analysers (Escalona et al., 2000) and heat balance sap flow gauges (De Lorenzi and Rana, 2000). While the last one is more suitable for trees and difficult to apply in annual crops, the porometers and gas analyser systems take measurement from the leaf itself (Dugas et al., 1993). However, the in situ use of these instruments is limited because obtaining measurements during the entire crop cycle and at a high time frequency is unfeasible. To tackle the problem, estimates of plant transpiration rates by numerical modelling can be used as a tool to assess high time frequency plant transpiration data (Olioso et al., 2005). In these models, input variables such as air or canopy temperature are used that can be measured easier and at higher frequency than transpiration.

A physical-mechanistic way to model the plant transpiration rate is to account for the conductance (or its inverse: resistance) of the water dissipation pathway through the canopy to the atmosphere and to relate the conductance to driving environmental forces like evaporation and total canopy leaf area. The leaf stomatal conductance is the most variable parameter on the pathway and in a physical approach of transpiration modelling it is related to the stomatal conductance, allowing to determine the inherent parameters of the process. This sort of relation was reported by pioneer physiologists like Farquhar et al. (1980) and Goudriaan et al. (1985), and derives from the observation that the exchange of water between the leaves and

(C) 2016 Institute of Agrophysics, Polish Academy of Sciences 
the atmosphere takes place in the gaseous phase of water, mostly through the stomata. Both in experimental studies (Cowan, 1982) and by numerical modelling (Jacobs et al., 1996), stomatal conductance has been shown to be related to net $\mathrm{CO}_{2}$ assimilation rate $A$, to the water vapour pressure deficit in the atmospheric air, to the specific vapour deficit between the intercellular leaf air spaces and the atmospheric air $D_{s}$, and to the intercellular $\mathrm{CO}_{2}$ concentration $C_{i}$. In $A g_{\mathrm{s}}$ models ( $A$ being the net $\mathrm{CO}_{2}$ assimilation rate and $g_{\mathrm{s}}$ the stomatal conductance to water vapour), the stomatal conductance to water vapour is derived based on the net $\mathrm{CO}_{2}$ assimilation rate calculated from mainly physically based parameterizations of the above variables (Jacobs, 1994; Albergel et al., 2010).

The $A g_{\text {s }}$ model proposed by Jacobs (1994) is based on the equations by Goudriaan et al. (1985), and describes the stomatal processes by parameterising the net $\mathrm{CO}_{2}$ assimilation responses to the environmental factors such as air humidity and temperature and radiation. However, as each of the variables affects the sensitivity of stomata to other factors, the model also describes the synergistic interactions between different stimuli. The model by Jacobs (1994) has been widely used in numerical schemes accounting for photosynthesis and carbon fluxes due mainly to its physical plant-environment representation. Examples are the meteorological model ECMWF (Boussetta et al., 2013) or the crop model WOFOST-SWAP (Supit et al., 2012; Van Dam et al., 2008), but its possible application in plant transpiration simulations is still open.

Jacobs (1994) used parameterizations disregarding the effect of water stress in plants by high atmospheric demand of water vapour or by soil water shortage. However, studies show that water stress affects the stomatal conductance, the $\mathrm{CO}_{2}$ assimilation and, consequently, introduces limits to the productivity and growth of plants (Lipiec et al., 2013). According to Galle et al. (2009), the limiting photosynthesis factors under these conditions and their possible interactions with other environmental conditions are still not very well understood. The increase in stomatal resistance of plant leaves to water vapour induced by water stress has been considered as equally limiting for $\mathrm{CO}_{2}$ assimilation, since the diffusion of $\mathrm{CO}_{2}$ from the carboxylation sites in the chloroplast to the atmosphere is hampered. However, the reduced $\mathrm{CO}_{2}$ assimilation rates during water stress events can be explained also by other factors, like internal leaf restrictions in the $\mathrm{CO}_{2}$ path from intercellular spaces to the mesophyll cells, to the chloroplasts and to the carboxylation sites (Galle et al., 2009).

The contribution of each internal leaf compartment to the reduction of $\mathrm{CO}_{2}$ assimilation during water stress events is not completely quantified (Warren, 2008). Observational studies show that both the $\mathrm{CO}_{2}$ compenzation point $\Gamma$, mesophyll conductance $g_{m}$, maximum $\mathrm{CO}_{2}$ assimilation rate $A_{m, \max }$ and dark respiration of photosynthesis $R_{d}$ vary significantly depending on the plant water status.
One of the first studies dealing with the effects of water stress on the $\mathrm{CO}_{2}$ compenzation point $\Gamma$ made by Smolander and Lappi (1984) showed $\Gamma$ to increase with the intensification of water stress and increasing leaf temperature in willow trees. Recently, a review by Srikanta Dani et al. (2015) indicated a general increase of leaf temperature and $\Gamma$ as a response of stomatal closure due to water stress. In sunflower plants, Tezara et al. (1999) observed $A_{m, \max }$ to decrease with water stress intensification whereas $\Gamma$ progressively increased over the same period. In vineyards, Escalona et al. (1999) reported a pronounced effect of soil water shortage on $A_{m, \max }$ with a reduction of $60 \%$ in relation to well watered plants. A decrease of $A_{m, \max }$ of the droughtsensitive European beech (Fagus sylvatica) tree species was also reported by Hommel et al. (2016). The mesophyll conductance $g_{m}$ decreased in response to water stress and to the abscisic acid production in studies by Flexas et al. (2006) and Galle et al. (2009), but $g_{m}$ can also change solely in response to water stress, usually decreasing as observed by Warren (2008). These results corroborate the hypothesis that $g_{m}$ plays an important role in the photosynthetic response of plants to climatic forcing (Flexas et al., 2008). The effect of water stress on the dark respiration $R_{d}$ is inconclusive. Some studies show a decrease of $R_{d}$ as a function of water stress (Galmés et al., 2007), whereas others report an increase (Zagdańska, 1995). According to Ribas-Carbo et al. (2005), changes in $R_{d}$ are smaller than in photosynthesis, causing a significant increase in the ratio of respiration/photosynthesis under water stress, and indicating the role of respiration to become more important with increasing water stress.

In the $A g_{s}$ model by Jacobs (1994), the variables $\Gamma$, $g_{m}, A_{m, \max }$ and $R_{d}$, fundamental to calculate the net $\mathrm{CO}_{2}$ assimilation, are empirically treated as a function of leaf temperature, limiting the model representation of plant physiology during the occurrence of water stress. To estimate the transpiration rate of a crop canopy, the net $\mathrm{CO}_{2}$ assimilation for each vertical canopy layer (leaf scale) is calculated by the extinction of photosynthetically active radiation $I_{P A R}$ inside the canopy, since the leaves at the top of the canopy intercept the majority of the downward solar radiation, reducing the photosynthetic activity of the lower canopy layers. The $I_{P A R}$ extinction inside the canopy follows Beer law of exponential extinction considering the angular distribution of leaves, as proposed by Roujean (1996). Under conditions of water stress, however, the extinction of $I_{P A R}$ by plants is no longer exponential because morphologic aspects of the leaves, like the angular distribution $G$, are modified (Archontoulis et al., 2011) and the $A g_{s}$ model by Jacobs (1994) is no longer adequate.

In this context, it was the objective of this study to shed more light on the relative importance of the variables affecting transpiration simulation of plants exposed to water stress. To do so, we compare modified versions of the Jacobs (1994) model with specific parameterizations of 
$\Gamma, g_{m}, A_{m, \max }, R_{d}$ and $G$ for dry conditions to the original Jacobs (1994) model. We use data from a field experiment in Brazil and correlate estimated plant transpiration rates to relevant environmental and plant variables by a principal component analysis.

\section{MATERIAL AND METHODS}

Experimental data were obtained from a $1000 \mathrm{~m}^{2}$ field plot, cropped with common bean (Phaseolus vulgaris L., Carioca cultivar), in Piracicaba, São Paulo State, Brazil $\left(22^{\circ} 42^{\prime} \mathrm{S}, 47^{\circ} 38^{\prime} \mathrm{E}\right)$ between June and September, 2010. The soil at the experimental plot is a Rhodic Kanhapludalf, according to USDA Soil Taxonomy. Bulk density is $1560 \mathrm{~kg} \mathrm{~m}^{3}$ in the Ap horizon $(0-0.2 \mathrm{~m})$ and $1380 \mathrm{~kg} \mathrm{~m}^{-3}$ in the Bt horizon $(0.2-0.8 \mathrm{~m})$. Clay content is 0.45 and $0.55 \mathrm{~kg} \mathrm{~kg}^{-1}$ in Ap and Bt horizon, respectively. Local climate is classified as humid subtropical, with dry winters and hot summers (Köppen Cwa), favourable for the cultivation of Common Bean. The annual rainfall is approximately $1300 \mathrm{~mm}$. However, in the dry winter months (June August), rainfall is almost absent and irrigation is required to successfully grow crops.

The area was divided in two subplots: one irrigated by sprinklers during the entire crop cycle (fully irrigated treatment - FI), the other one subject to water stress in the reproductive phase between August 4 and September 1 (deficit irrigated treatment-DI). The time interval between August 4 and September 2 was defined as the study period in this paper as it was the period during the crop cycle when plants on the two plots were subjected to distinctly different soil water conditions. Relative air humidity $\left(H_{R}, \%\right)$ and air temperature $\left(t_{\text {air }},{ }^{\circ} \mathrm{C}\right)$ were measured at a height of $2 \mathrm{~m}$ above the centre of each irrigation treatment, using a Campbell Scientific CS215L9 probe connected to a CR1000 datalogger. Canopy temperature $\left(t,{ }^{\circ} \mathrm{C}\right)$ was measured via two automated infrared thermometers (Apogee model SI111, target area of $65 \mathrm{~m}^{2}$ ), one per treatment, connected to the same data-logger. For measurements of soil water pressure head ( $h, \mathrm{MPa}$ ), polymer tensiometers (Bakker et al., 2007; Van der Ploeg et al., 2008) were used, with a measurement range between 0 and $1.47 \mathrm{MPa}(-150 \mathrm{~m})$. Soil water pressure head was measured at $0.05,0.1$ and $0.3 \mathrm{~m}$ depth at two observation points per subplot (two observation points (identified as 1 and 2) in the fully irrigated treatment, and two observation points ( 3 and 4 ) in the deficit irrigated treatment). All measurements were performed every $30 \mathrm{~min}$ averaging the previous period. To avoid including the impact of irrigation water on temperatures and atmospheric vapour pressure in the data set, data obtained during irrigation events were excluded from further analysis.

The leaf area index $\left(L_{L A l}, \mathrm{~m}^{2} \mathrm{~m}^{-2}\right)$ was measured by an indirect and non-destructive method with a ceptometer. Plant Canopy Analyser, model LAI $2000^{\circledR}$ from Li-Cor. LAI measurements were taken five times per each irriga- tion treatment during the experimental period, on August 4, 12, 19 and 27 and on September 2. Daily values of $L_{L A I}$ were obtained by linear interpolation between the measurements, and ranged from 3.37 to $5.70 \mathrm{~m}^{2} \mathrm{~m}^{-2}$ in the fully irrigated treatment and between 2.49 and $3.37 \mathrm{~m}^{2} \mathrm{~m}^{-2}$ in the deficit irrigated treatment.

During the 90 days of the field experiment (June 15 September 13), rainfall was observed on July 13, 14 and 15 (63 $\mathrm{mm}$ in total) and then again, after more than 50 days, on September $7(13 \mathrm{~mm})$ during the ripening period. In the periods between August 2 and 23 and between August 25 and September 1, only the fully irrigated treatment was irrigated. On August 24, a small irrigation $(\sim 15 \mathrm{~mm})$ was performed on the deficit irrigated treatment to guarantee the survival of the crop. In total (rainfall + irrigation), the fully irrigated treatment received $426.5 \mathrm{~mm}$ of water and the deficit irrigated treatment received $314.5 \mathrm{~mm}$. Additional measurements and experimental details are described in Durigon et al. (2012).

Plant transpiration simulations were performed using the $A g_{\mathrm{s}}$ model by Jacobs (1994) and Jacobs et al. (1996). The theoretical description of model parameterizations is presented in the original publications. The $A g_{s}$ model was numerically programmed using Fortran programming language and the source code was described in Durigon (2011). In the original model, the relationship between stomatal conductance to water vapour $g_{s}$, expressed in $\mathrm{mm} \mathrm{s}^{1}$, and net $\mathrm{CO}_{2}$ assimilation $A\left(\mathrm{mg} \mathrm{m}^{2} \mathrm{~s}^{1}\right)$ is given, as a first approximation, by:

$$
g_{s}=1.6 g_{s c}=1.610^{3} \frac{A}{C_{s}-C_{i}},
$$

where: the factor 1.6 is the ratio between air diffusivities of $\mathrm{H}_{2} \mathrm{O}$ and $\mathrm{CO}_{2}, g_{s c}\left(\mathrm{~mm} \mathrm{~s}^{1}\right)$ is the stomatal conductance to $\mathrm{CO}_{2}, C_{s}$ and $C_{i}\left(\mathrm{mg} \mathrm{m}^{3}\right)$ are the $\mathrm{CO}_{2}$ concentrations at the leaf surface and the intercellular air spaces in the leaves, respectively, parameterised as a function of specific humidity deficit between leaf and air, $D_{s}\left(\mathrm{mg} \mathrm{kg}^{1}\right)$, defined as:

$$
D_{s}=q_{s}\left(t_{c}\right)-q_{\text {air }} .
$$

In this equation, $q_{\mathrm{s}}\left(t_{c}\right)$ is the specific humidity at saturation $\left(\mathrm{mg} \mathrm{kg}^{\mathrm{l}}\right)$ as a function of canopy temperature $t_{c}$ and $q_{\text {air }}$ is the specific humidity of the atmospheric air near leaves $\left(\mathrm{mg} \mathrm{kg}^{1}\right)$.

Assuming a vertical distribution of leaves, net $\mathrm{CO}_{2}$ assimilation $A$ and stomatal conductance $g_{s}$ are given by:

$$
\begin{gathered}
A=\frac{L_{L A I}}{h_{p}} \int_{0}^{h} A d z, \\
g_{s}=\frac{L_{L A I}}{h_{p}} \int_{0}^{h} g_{s} d z,
\end{gathered}
$$

in which $L_{L A I}\left(\mathrm{~m}^{2} \mathrm{~m}^{-2}\right)$ is the leaf area index, $h_{p}(\mathrm{~m})$ is 
plant height and $d z(\mathrm{~m})$ is a height interval. The integrals are solved by applying a five-point Gaussian quadrature scheme eg:

$$
\begin{gathered}
A=\frac{L_{L A I}}{h_{p}} \sum_{i=1}^{5} W_{i} A\left(z_{i}\right), \\
g_{s}=\frac{L_{L A I}}{h_{p}} \sum_{i=1}^{5} W_{i} g_{s}\left(z_{i}\right),
\end{gathered}
$$

where: $z_{i}$ and $W_{i}$ are distance and weight of point $i$, respectively, and values are presented in Durigon (2011).

The plant transpiration rate $T\left(\mathrm{mg} \mathrm{m}^{-2} \mathrm{~s}^{-1}\right)$ is determined by the total conductance to the water vapour flux $g_{t}\left(\mathrm{~mm} \mathrm{~s}^{-1}\right)$ :

$$
\begin{gathered}
T=10^{-3} \rho_{\text {air }} g_{t} D_{s} L_{L A I}, \\
g_{t}=g_{s}+g_{m}+2 g_{b l},
\end{gathered}
$$

where: $\rho_{\text {air }}$ is the air density $\left(1.2 \mathrm{~kg} \mathrm{~m}^{-3}\right.$ at $\left.15^{\circ} \mathrm{C}\right)$ and $g_{b l}$ $\left(\mathrm{mm} \mathrm{s}^{-1}\right)$ is the boundary layer conductance around leaf calculated by:

$$
g_{b l}=k\left(\frac{u}{W_{l}}\right)^{0.5},
$$

in which $k$ is an empirical constant $\left(5.6 \mathrm{~mm} \mathrm{~s}^{-0.5}\right), u$ is the wind speed $\left(\mathrm{mm} \mathrm{s}^{1}\right)$ and $W_{1}$ is the leaf width parallel to wind (assumed to be $100 \mathrm{~mm}$ ). The cuticular conductance was considered negligible when compared to other conductances and was not included in Eq. (6). Multiplication of $g_{b l}$ by 2 allows accounting for both sides of leaves.

As mentioned in the introduction, the variables $\Gamma, g_{m}$, $A_{m \text {,max }}, R_{d}$ and $G$ are treated in a semi-empirical way in the $A g_{s}$ model by functions shown in Fig. 1 as solid black lines. The response of $\Gamma$ to the temperature is given by a $Q_{10}$ function, a simplification of the Arrhenius function:

$$
\Gamma=\Gamma_{25} Q_{10} \frac{t_{c}-25}{10},
$$

in which $t_{c}$ is the canopy temperature in ${ }^{\circ} \mathrm{C}$, and $\Gamma_{25}$ is the value of $\Gamma$ at $t_{\mathrm{c}}=25^{\circ} \mathrm{C}$. Both $\Gamma_{25}$ and $Q_{10}$ for $\Gamma$ estimation are presented in Table 1.

To obtain $g_{m}$ and $A_{m, \max }$, a generic equation is used:

$$
X\left(t_{c}\right)=\frac{x_{25} Q_{10}{ }^{\frac{t_{c}-20}{10}}}{\left(1+\exp \left(0.3\left(t_{1}-t_{c}\right)\right)\right)\left(1+\exp \left(0.3\left(t_{c}-t_{2}\right)\right)\right)},
$$

where: $X\left(t_{\mathrm{c}}\right)$ is the value of $g_{m}$ or $A_{m, \max }$ at temperature $t_{c}, t_{1}$ and $t_{2}$ represent reference temperatures and need to be adjusted to minimise the specific species characteristics (eg the optimum temperature for plants with a $\mathrm{C}_{3}$ photosynthetic pathway is lower than for plants with a $\mathrm{C} 4$ phosynthetic pathway), and $X_{25}$ is the value of $g_{m}$ or $A_{m, \text { max }}$ at $t_{c}=25^{\circ} \mathrm{C}$ $\left(g_{m, 25}\right.$ and $\left.A_{m, \max , 25}\right)$. Both $Q_{10}, X_{25}$ and reference temperatures to the $g_{m}$ and $A_{m, \text { max }}$ estimation by the original Jacobs model are presented in Table 1. a

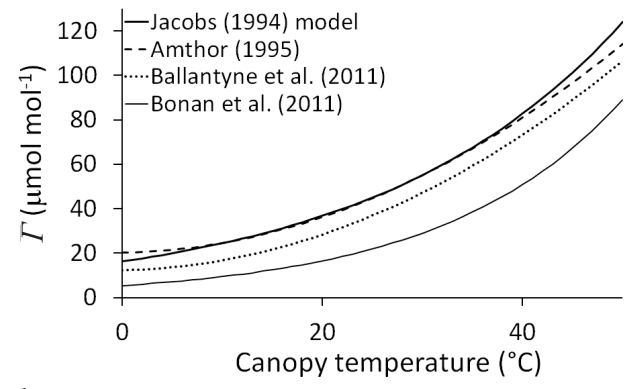

b

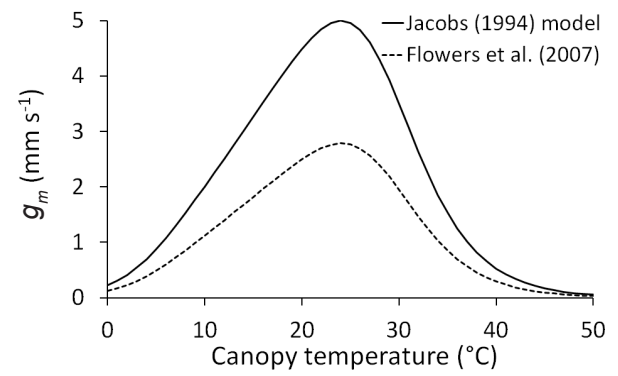

c

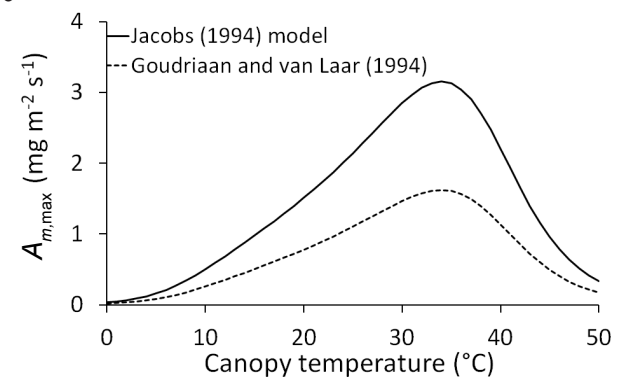

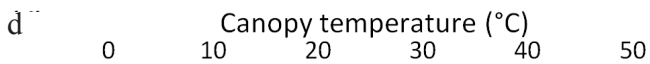
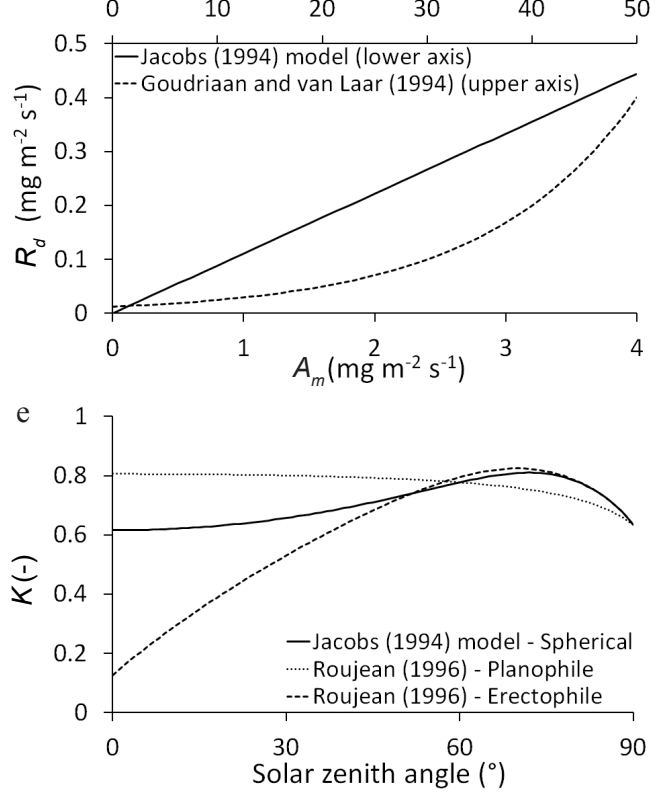

Fig. 1. Parameters used by the original $\mathrm{Ag}$ model by Jacobs (1994) and in this study $\left(\Gamma-\mathrm{CO}_{2}\right.$ compensation point, $g_{m}-$ mesophyll conductance, $A_{m, \text { max }}$ - maximum $\mathrm{CO}_{2}$ assimilation rate, $R_{d}$ - dark respiration of photosynthesis, $K$ - total light extinction coefficient (function of leaf angle distribution $G$ )). 
T a b l e 1. Parameters used by the original $A g_{s}$ model by Jacobs (1994) and used in this study

\begin{tabular}{lcccc}
\hline Parameter $(X)$ & $X_{25}$ & $Q_{10}$ & $t_{1}\left({ }^{\circ} \mathrm{C}\right)$ & $t_{2}\left({ }^{\circ} \mathrm{C}\right)$ \\
\hline$\Gamma\left(\mu \mathrm{mol} \mathrm{mol}{ }^{-1}\right)$ & 45 & 1.5 & - & - \\
$A_{m, \text { max }}\left(\mathrm{mg} \mathrm{m}^{-2} \mathrm{~s}^{-1}\right)$ & 2.2 & 2 & 8 & 38 \\
$g_{m}\left(\mathrm{~mm} \mathrm{~s}^{-1}\right)$ & 7 & 2 & 5 & 28 \\
\hline
\end{tabular}

To estimate $R_{d}$, the following relation is used:

$$
R_{d}=\frac{A_{m}}{9},
$$

where: $A_{m}\left(\mathrm{mg} \mathrm{m}^{2} \mathrm{~s}^{1}\right)$ is the photosynthetic rate at saturating light intensity.

To upscale the $A g_{s}$ model by Jacobs (1994) from leaf to canopy transpiration, a spherical leaf angle distribution was considered, represented by parameter $G(G=0.5)$ in the extinction coefficient of direct light $K_{d r}(z)$ (Calvet et al., 1998):

$$
K_{d r}(z)=1-\exp \left(-\frac{G}{\cos \left(\theta_{s}\right)} b L_{L A I} \frac{h_{p}-z}{h_{p}}\right),
$$

in which $\theta_{s}\left(^{\circ}\right)$ is the solar zenith angle, $b$ is the foliage scattering coefficient, $h_{p}(\mathrm{~m})$ is the plant height and $z(\mathrm{~m})$ is a level above the soil surface. The total light extinction coefficient $K(z)$ between the top of the canopy and the level $z$ is expressed by:

$$
K(z)=f\left(\theta_{s}\right) K_{d f}(z)+\left(1-f\left(\theta_{s}\right)\right) K_{d r}(z),
$$

where: $K_{d d}(z)$ is the is the extinction coefficient of diffuse light and $f\left(\theta_{s}\right)$ is the ratio of diffuse to total solar radiation at the top of the canopy which is given by:

$$
f\left(\theta_{\mathrm{s}}\right)=\frac{0.25}{0.25+\cos \left(\theta_{\mathrm{s}}\right)} .
$$

A systematic literature review was performed to retrieve parameterizations or parameter values of $\Gamma, g_{m}, A_{m, \text { max }}$, $R_{d}$ and $G$ different from the ones used in the original $A g_{\text {s }}$ model and which could better represent the environmental water stress condition. A systematic literature review is a standard procedure performed for the survey of available information (Ganann et al., 2010). Our systematic literature review consisted of the combination of the terms ' $\mathrm{CO}_{2}$ compenzation point', 'mesophyll conductance', 'maximum $\mathrm{CO}_{2}$ assimilation', 'dark respiration', and 'leaf angle distribution' to each of the terms 'parameterization' and ' $\mathrm{C}_{3}$ ' (referring to $\mathrm{C}_{3}$ plants), and a main search was performed in the Google Scholar database of June 2015, defining the specific publication time interval from 1990 to 2015. The number of publications retrieved for each combination of terms is listed in Table 2. Among these publications, a detailed selection was performed to identify parameterizations that could be used in the $A g_{s}$ model. Compiling these publications, a final set of 8 parameterizations was obtained and added to the $A g_{s}$ model. The number of publications selected and the number of parameterizations added to the $A g_{s}$ model for each combination of terms are listed in Table 2. Although a relatively high number of publications presented parameterizations that could be used in the model (107 publications in total), most of these refer to the same parameterizations. This indicates that a few mathematical representations of the biochemical variables related to the $\mathrm{CO}_{2}$ assimilation process are actually used in crop modelling.

The functions representing $\Gamma, g_{m}, A_{m, \max }, R_{d}$ and $G$ in the original Jacobs (1994) model were replaced by functions obtained for $\mathrm{C}_{3}$ plants in the systematic literature review. The new functions added to the model are also shown in Fig. 1. To modify the $\Gamma$ function in the original $A g_{\mathrm{s}}$ model, three new functions were used (Fig. 1a). In the first one, described by Amthor (1995), the $\mathrm{CO}_{2}$ compenzation point $\Gamma$ is a quadratic function of canopy temperature $t_{c}\left({ }^{\circ} \mathrm{C}\right)$ :

$$
\Gamma=44.7+1.88\left(t_{c}-25\right)+0.036\left(t_{c}-25\right)^{2} .
$$

A second, very similar function was proposed by Ballantyne et al. (2011):

\begin{tabular}{|c|c|c|c|}
\hline $\begin{array}{l}\text { Term combined to } \\
\text { 'parameterization' and ' } \mathrm{C}_{3} \text { ' } \\
\text { terms }\end{array}$ & Publications retrieved & Publications selected & $\begin{array}{l}\text { Parameterizations added } \\
\text { to the } A g_{s} \text { model }\end{array}$ \\
\hline $\mathrm{CO}_{2}$ compensation point & 196 & 51 & 3 \\
\hline Mesophyll conductance & 190 & 17 & 1 \\
\hline Maximum $\mathrm{CO}_{2}$ assimilation & 10 & 7 & 1 \\
\hline Dark respiration & 493 & 17 & 1 \\
\hline Leaf angle distribution & 171 & 16 & 2 \\
\hline
\end{tabular}

$$
\Gamma=36.9+1.88\left(t_{c}-25\right)+0.036\left(t_{c}-25\right)^{2} .
$$

T a b l e 2. Number of publications retrieved in the systematic literature review, publications selected and parameterizations added to the $\mathrm{Ag}_{s}$ model for combination of the search term combined to terms 'parameterization' and ' $\mathrm{C}_{3}$ ' 
The third function was presented by Bonan et al. (2011) who estimated $\Gamma$ from the dependence of the MichaelisMenten coefficients to $\mathrm{O}_{2}$ and $\mathrm{CO}_{2}$ diffusion to the canopy temperature:

$$
\begin{gathered}
\Gamma=0.5 \frac{K_{c}}{K_{o}} 0.21 O, \\
K_{c}=K_{c 25} f\left(t_{C}\right) ; Q_{10}=2.1, \\
K_{o}=K_{o 25} f\left(t_{C}\right) ; Q_{10}=1.2, \\
f\left(t_{C}\right)=Q_{10} \frac{\left(t_{C}-298.15\right)}{10},
\end{gathered}
$$

where: $K_{c}$ and $K_{o}$ are the Michaelis-Menten coefficients for $\mathrm{CO}_{2}$ and $\mathrm{O}_{2}$, respectively, $\mathrm{O}$ is the atmospheric $\mathrm{O}_{2}$ concentration $\left(0.209 \mathrm{~mol} \mathrm{~mol}^{-1}\right), K_{c 25}(30 \mathrm{~Pa})$ and $K_{o 25}$ $(30000 \mathrm{~Pa})$ are the Michaelis-Menten coefficients for $\mathrm{CO}_{2}$ and $\mathrm{O}_{2}$ at $25^{\circ} \mathrm{C}$, respectively, $f\left(t_{C}\right)$ is the temperature dependence function of $K_{c}$ and $K_{o}$, and $t_{C}$ is the absolute canopy temperature $(\mathrm{K})$. In the normal canopy temperature range, all three functions represent a similar increase of $\Gamma$, but slightly greater $\Gamma$ values are obtained from the functions of the original model, of Amthor (1995) and of Ballantyne et al. (2011), as compared to the Bonan et al. (2011) function. All of them are supported by observations presented by Smolander and Lappi (1984) who showed $\Gamma$ to increase with the intensification of water stress and increasing leaf temperature in willow trees (Salix babylonica).

The original Jacobs (1994) simulations are based on $g_{m}=7 \mathrm{~mm} \mathrm{~s}^{1}$ under ideal soil hydraulic conditions at $25^{\circ} \mathrm{C}$, in agreement with Nobel (1991). Flowers et al. (2007) reported a value of $g_{m}=3.9 \mathrm{~mm} \mathrm{~s}^{1}$ for $\mathrm{C}_{3}$ plants under water stress at $25^{\circ} \mathrm{C}$. We replaced the original value of $7 \mathrm{~mm} \mathrm{~s}^{1}$ by $3.9 \mathrm{~mm} \mathrm{~s}^{1}$, which introduced a large change in the $g_{m}$ function (Fig. 1b). The maximum value of $g_{m}$ equals $5 \mathrm{~mm}$ $\mathrm{s}^{-1}$ in the original model, but using the Flowers et al. (2007) observation it reduces to $2.79 \mathrm{~mm} \mathrm{~s}^{-1}$, both at $t_{c}=24^{\circ} \mathrm{C}$.

For $A_{m \text {,max }}$, the original function was replaced by:

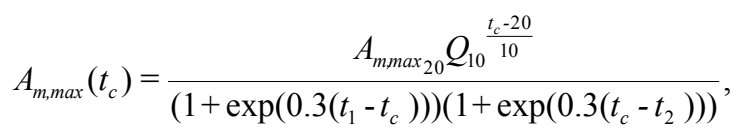

in which $A_{m, \text { max }}$ at $20^{\circ} \mathrm{C}\left(A_{m, \text { max 20 }}\right)$ is assumed equal to $0.8 \mathrm{mg}$ $\mathrm{m}^{-2} \mathrm{~s}^{1}$, replacing the value for $25^{\circ} \mathrm{C}$, and the exponential of the $Q_{10}$ function was modified following Goudriaan and van Laar (1994) (Fig. 1c). Using the new parameterization, the maximum $A_{m, \text { max }}$ is equal to $1.62 \mathrm{mg} \mathrm{m}^{2} \mathrm{~s}^{-1}$ while the maximum $A_{m, \text { max }}$ in the original model is equal to $3.15 \mathrm{mg}$ $\mathrm{m}^{-2} \mathrm{~s}^{-1}$, both at $t_{c}=34^{\circ} \mathrm{C}$. The lower maximum of the new $A_{m \text {,max }}$ function curve could indicate that it better represents the water stress condition following observations of Tezara et al. (1999) and Escalona et al. (1999), who reported $A_{m, \max }$ to decrease in water stress occurrences.
$R_{d}$ as a function of canopy temperature was estimated using the function proposed by Goudriaan and van Laar (1994):

$$
R_{d}=R_{d 20} Q_{10}^{\left(\frac{t_{c}-20}{10}\right)},
$$

where: $R_{d 20}$ is dark respiration at $20^{\circ} \mathrm{C}\left(=0.05 \mathrm{mg} \mathrm{m}^{-2} \mathrm{~s}^{-1}\right)$ and $Q_{10}$ was taken as 2 (Fig. 1d). While the original $R_{d}$ parameterization is a linear function of $A_{m}$, the modified function is exponential with $t_{C}$, but both parameterizations agree with the observations of Zagdańska (1995) who indicated $R_{d}$ to increase as plants became water stressed, closing stomata and reducing transpiration, causing higher leaf temperatures.

Leaf angle distribution was modified from the spherical, as used in Jacobs (1994) distributions suggested by Roujean (1996), to planophile:

$$
G=\cos \theta_{s},
$$

or to erectophile:

$$
G=\frac{2}{\pi} \sin \theta_{\mathrm{s}} .
$$

The three distributions are illustrated in Fig. 1e. The spherical function implies lower sensitivity to the solar zenith angle $q_{s}$ of light absorption by the canopy (related to the light extinction coefficient $K$ ). Using $b=0.9442$, $L_{L A I}=4 \mathrm{~m}^{2} \mathrm{~m}^{-2}, h_{p}=0.6 \mathrm{~m}$ and $z=0.4 \mathrm{~m}$, the resulting $K$ is around 0.7 . The planophile function simulates higher light interception, making it less sensitive to the solar zenith angle. The erectophile function, on the other hand, reduces interception, making it more sensitive to the solar zenith angle, extinguishing less light as $\theta_{s}$ decreases. This is, in fact, a behaviour adopted by plants under water stress to avoid an excessive radiation load during the warmest hours of the day. Atti et al. (2005), for example, experimentally observed that soybean plants changed their leaf angle distribution of spherical to erectophile as a function of soil water shortage.

To evaluate the performance of the simulations, predicted canopy temperatures were compared to measurements. Canopy temperature was calculated by the energy balance approach, using hourly net radiation measured in the weather station near the experiment, the transpiration rate estimated by the $A g_{s}$ model to calculate the latent heat flux, and assuming the soil heat flux to be equal to zero in fully closed vegetated surfaces (Allen et al., 1998).

Three statistical indices were used for model performance quantification:

- root-mean-square error of prediction $\left(R M S E P,{ }^{\circ} \mathrm{C}\right)$ :

$$
R M S E P=\sqrt{\sum_{i=1}^{n} \frac{\left(t_{c, i}-\hat{t}_{c, i}\right)^{2}}{n}},
$$


- mean error $\left(M E,{ }^{\circ} \mathrm{C}\right)$ :

$$
M E=\frac{1}{n} \sqrt{\sum_{i=1}^{n}\left(t_{c, i}-\hat{t}_{c, i}\right)},
$$

- efficiency coefficient $E$ (Nash and Sutcliffe,1970):

$$
E=1-\frac{\sum_{i=1}^{n}\left(t_{c, i}-\hat{t}_{c, i}\right)^{2}}{\sum_{i=1}^{n}\left(t_{c, i}-\bar{t}_{c, i}\right)^{2}},
$$

where: $t_{\mathrm{c}}$ and $\hat{t}_{c}$ are observed and estimated values of canopy temperature, respectively, $\bar{t}_{c}$ is the mean of observed values and $n$ is the total number of observations.

Many environmental (soil and atmosphere) and plant variables act together to determine the plant transpiration rate. The relative importance of each of these components can be evaluated using a principal component analysis (PCA) (Abdi and Williams, 2010), a specific statistical methodology to explain a process governed by a large set of variables in terms of a smaller set. It allows the interpretation of a process by comprising the maximum information of an initial data set measured through the total variance of two or three representative components with an appropriate function of the total variance. The add-in NumXL available in Microsoft Excel 2013 was used to perform the PCA.

The principal component analysis (PCA) was performed in two ways for both irrigation treatments: by taking the transpiration rate data series together with the environmental and plant input variables, and by taking only the data series of the environmental and plant input variables (named as $E P$ ), aiming to characterise the plant transpiration controlling environment. The environmental and plant variables used in the PCA were the specific humidity deficit between stomata and air $\left(D_{s}\right)$, the photosynthetically active radiation $\left(I_{P A R}\right)$, the relative humidity $\left(H_{R}\right)$, canopy and air temperature $\left(t_{c}\right.$ and $\left.t_{\text {air }}\right)$, the wind speed $(u)$, and the leaf area index $\left(L_{L A I}\right)$. In addition, time series of the atmospheric water potential $(\psi, \mathrm{MPa})$ and the mean soil water pressure head $\left(h_{m}, \mathrm{MPa}\right)$ were included in the PCA as environmental variables. The atmospheric water potential and the soil water pressure head decrease when air and soil get dry, and the difference between these two variables, represent the main driving force to water flow in the soil-plant-atmosphere continuum.

The atmospheric water potential $\psi(\mathrm{MPa})$ can be calculated from air absolute temperature $t_{A I R}(\mathrm{~K})$ and relative humidity $H_{R}$ (here in $\mathrm{Pa} \mathrm{Pa}^{-1}$ ) by:

$$
\Psi=9.810^{-3} \frac{t_{A I R} R}{\rho_{w} g v_{w}} H_{R},
$$

with $R$ being the gas constant $\left(R=8.31 \mathrm{~J} \mathrm{~mol}^{-1} \mathrm{~K}^{-1}\right)$, $r_{w}$ and $v_{w}$ the density and molar volume of liquid water (here considered as $r_{w}=1000 \mathrm{~kg} \mathrm{~m}^{-3}$ and $v_{w}=1.810^{5} \mathrm{~m}^{3}$ $\left.\mathrm{mol}^{1}\right)$, respectively, and $g$ the gravitational acceleration $\left(g=9.81 \mathrm{~m} \mathrm{~s}^{2}\right)$. The atmospheric water potential was estimated by Eq. (27) using air relative humidity and temperature measured for each treatment every $30 \mathrm{~min}$.

The mean soil water pressure head $h_{m}(\mathrm{MPa})$ experienced by the root system of plants at each observation point (three depths at two observation points per irrigation treatment) was calculated using root distribution over depth as weighing factor. During the reproductive phase, the root system was supposed to be completely developed, and therefore we assumed a constant relative root length distribution over time. For our simulations, root length distribution for Phaseolus vulgaris L. as described by Guimarães et al. (1993) was used. His experimental work was done in climatic and soil conditions similar to our experiment and with the same crop cultivar, reporting almost $50 \%$ of the total root length in the upper $25 \%$ of the rooted profile $(0-0.1 \mathrm{~m})$, another $25 \%$ in the second $25 \%$ of the profile (0.1-0.2 m), while the bottom $50 \%$ of the profile accounted for approximately $25 \%$ of the total root length $(0.20 .4 \mathrm{~m})$. In agreement with these measurements, we assumed $h_{m}$ equal to:

$$
h_{m, i}=0.5 h_{1, i}+0.25 h_{2, i}+0.25 h_{3, i},
$$

where: the subscript $i$ indicates the observation point in the field ( 1 and 2 in the fully irrigated treatment, and 3 and 4 in the deficit irrigated treatment), and $h_{1}, h_{2}$ and $h_{3}(\mathrm{MPa})$ are the soil water pressure heads measured at $0.05,0.1$ and 0.3 $\mathrm{m}$ depth, respectively.

Before applying a PCA, a detrending operation was applied to separate the simulated transpiration $\left(T_{F I}\right.$ and $\left.T_{D I}\right)$ data sets in temporal components. Detrending is the statistical or mathematical technique of removing trends from data sets (Moran et al., 2009). Two main trends are usually observed in transpiration data: a daily trend correlated to the daily radiation cycle, and a long term trend correlated to soil water availability. Detrending was performed on the transpiration rate estimated every $30 \mathrm{~min}$ in daytime by the best performing $A g_{\mathrm{s}}$ model (the model version showing the best statistical indices) to remove the long term trend. Initially, time-dependent polynomial equations were fitted to the transpiration rate data series between August 4 (day 0) and September 2 (day 29). For the fully irrigated treatment, a first-degree polynomial equation was used, and for the deficit irrigated treatment a third-degree polynomial equation showed the best performance. The long term transpiration rate $T_{l t}$ was then calculated by the fitted polynomial equations for each irrigation treatment $\left(T_{l, F I}\right.$ and $\left.T_{l t, D I}\right)$ :

$$
T_{l t, F I}=a+b \tau,
$$

and

$$
T_{l t, D I}=c+d \tau+e \tau^{2}+f \tau^{3},
$$


where: $\tau$ is the time (d) and $a, b, c, d, e$ and $f$ are fitting parameters.

For each treatment, the daily component of transpiration $\left(T_{\text {daily,FI }}\right.$ and $\left.T_{\text {daily, DI }}\right)$ was calculated by:

$$
T_{\text {daily,FI }}=\left(T_{F I}-T_{l, F I}\right)+T_{\min T l t, F I},
$$

and

$$
T_{\text {daily,DI}}=\left(T_{D I}-T_{l t, D I}\right)+T_{\min T l t, D I} .
$$

The addition of the minimum values of $T_{l t}$ to the difference forces transpiration rates to be positive, thus preserving their physiological meaning.

In addition to daily and long term trends in transpiration rates, a third trend that is frequently observed is a transpiration reduction during the warmest hours of the day, sometimes referred to as the afternoon depression of photosynthesis (Wang et al., 2006). Even when soil water conditions are favourable, stomatal closure is observed due to high atmospheric demand for water vapour. Leuning (1995) and Tuzet et al. (2003) explained in details the afternoon depression of photosynthesis. According to those authors, stomatal conductance depends not only on net radiation, temperature and intercellular $\mathrm{CO}_{2}$ concentration via photosynthesis, but also on leaf water potential, which is in turn a function of soil water potential and water flux rate between soil and plant. During the hours of very high atmospheric demand, the combined soil-plant resistance is too high to provide sufficient water, and a depression of photosynthesis can develop by stomatal closure. As a result, the canopy temperature at midday has a maximum value (Wang et al., 2006). Using canopy temperature data measured by infrared thermometry as input in the $A g_{s}$ model, that uses the vapour pressure deficit between intercellular air spaces of leaves and atmospheric air as the driving force for the diffusion of vapour, the afternoon depression of photosynthesis can be simulated (Jones, 2004) and included in estimated transpiration rates. Days that presented this feature in the $T_{\text {daily }}$ component were selected and the simulated transpiration rates, identified as $T_{d, F I}$ and $T_{d, D I}$ for the fully and deficit irrigated treatments, respectively, were also analysed with the PCA methodology.

\section{RESULTS AND DISCUSSION}

To quantitatively evaluate the model performance with all parameterizations, statistical indices RMSEP, ME and $E$ of estimated and observed canopy temperature $t_{c}$ are presented in Table 3 for both irrigation treatments. Values of $R M S E$ and $M E$ closer to zero indicate good model prediction compared to the observations, while the coefficient of efficiency $(E)$ ranges from $-\infty$ to 1 , with positive values indicating that model predictions are better than the simple data average. The most important error decrease in $t_{c}$ estimation and an increase in model efficiency were observed when the $g_{m}$ parameterization was modified. Changes in $\Gamma, A_{m, \max }$ and $R_{d}$ parameterizations did not effectively alter model performance when compared to the original model. The Amthor (1995) function for $G$ is close to the original one and presented almost the same statistical performance, while the functions of Ballantyne et al. (2011) and Bonan et al. (2011) result in smaller values of $\Gamma$ than the original function increased the error of prediction. This indicates that greater values of $\Gamma$ with $t_{c}$ better represent a water stress condition. The Flowers et al. (2007) parameterization for $A_{m, \text { max }}$ reduced prediction errors, indicating that the new function for $A_{m \text { max }}$ with a low peak would better represent a condition of water stress. Inserting the parameterization

T a b l e 3. Root-mean-square error of prediction $R M S E P\left({ }^{\circ} \mathrm{C}\right)$, mean error $M E\left({ }^{\circ} \mathrm{C}\right)$ and coefficient of efficiency $E$ of the canopy

\begin{tabular}{|c|c|c|c|c|c|c|}
\hline \multirow{2}{*}{ Parameterization } & \multicolumn{2}{|c|}{$\operatorname{RMSEP}\left({ }^{\circ} \mathrm{C}\right)$} & \multicolumn{2}{|c|}{$M E\left({ }^{\circ} \mathrm{C}\right)$} & \multicolumn{2}{|c|}{$E$} \\
\hline & $F I$ & $D I$ & FI & $D I$ & $F I$ & $D I$ \\
\hline Original Jacobs (1994) model & 8.09 & 7.32 & 3.54 & 2.32 & -1.24 & 0.1 \\
\hline$\Gamma$-Amthor (1995) & 8.10 & 7.32 & 3.55 & 2.32 & -1.24 & 0.1 \\
\hline$\Gamma$ - Ballantyne et al. (2011) & 8.21 & 7.41 & 3.62 & 2.38 & -1.3 & 0.08 \\
\hline$\Gamma$ - Bonan et al. (2011) & 8.41 & 7.58 & 3.73 & 2.47 & -1.42 & 0.04 \\
\hline$g_{m}-$ Flowers et al. (2007) & 5.91 & 6.43 & -0.81 & -1.28 & -0.19 & 0.3 \\
\hline$A_{m, \text { max }}-$ Goudriaan and van Laar (1994) & 7.85 & 7.19 & 3.25 & 2.12 & -1.11 & 0.13 \\
\hline$R_{d}$ - Goudriaan and van Laar (1994) & 8.24 & 7.38 & 3.64 & 2.32 & -1.32 & 0.09 \\
\hline G Planophile-Roujean (1996) & 8.39 & 7.67 & 3.32 & 2.23 & -1.41 & 0.02 \\
\hline$G$ Erectophile-Roujean (1996) & 8.08 & 7.26 & 3.64 & 2.35 & -1.23 & 0.12 \\
\hline
\end{tabular}
temperature estimated by the original $A g_{s}$ model by Jacobs (1994) and by the model with new parameterizations 


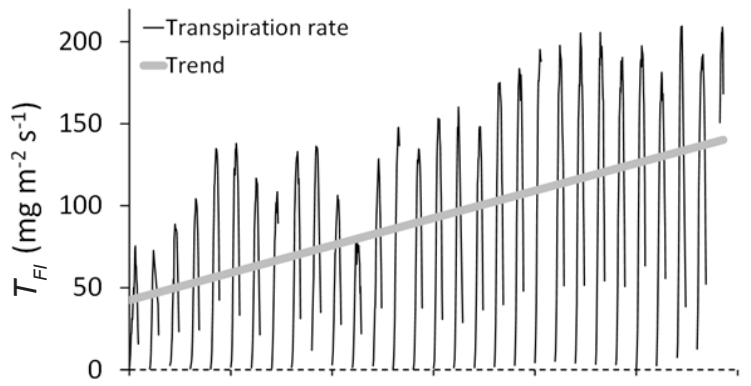

$\mathrm{b}$

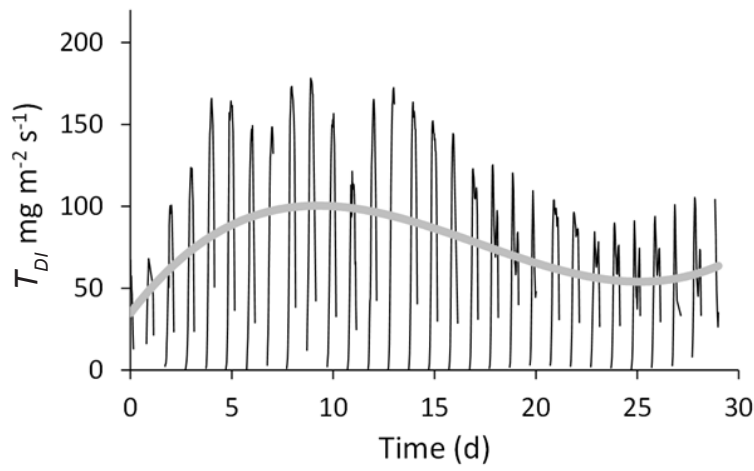

Fig. 2. Plant transpiration rate estimated by the $A g_{s}$ model for: $\mathrm{a}$ - the fully irrigated treatment (TFI, $\left.\mathrm{mg} \mathrm{m}^{-2} \mathrm{~s}^{-1}\right)$, and $\mathrm{b}$ - the deficit irrigated treatment $\left(T D I, \mathrm{mg} \mathrm{m}^{-2} \mathrm{~s}^{-1}\right)$ which presented the best statistical indices $\left(g_{m, 25}=3.9 \mathrm{~mm} \mathrm{~s}^{-1}\right.$ for the $F I$ and $g_{m, 25}=4.4 \mathrm{~mm} \mathrm{~s}^{-1}$ for the $D I)$ and the respective temporal trends $\left(F I: T_{F I}=42.455+\right.$ $3.337 \tau ; \mathrm{R}^{2}=0.22 ; T_{D I}=34.764+16.175 \tau-1.196 \tau^{2}+0.0232 \tau^{3}$; $\left.\mathrm{R}^{2}=0.13\right)$.

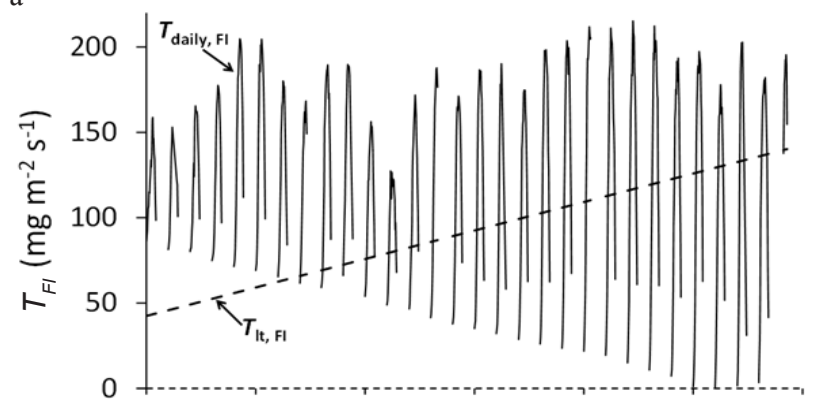

b

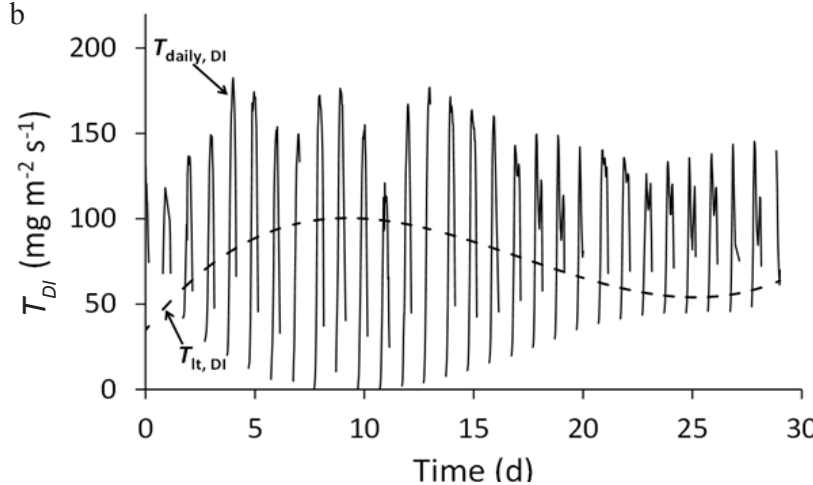

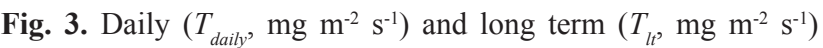
components of plant transpiration rate for: a - the fully irrigated treatment $\left(T_{d a i l,},{ }_{F I}\right.$ and $\left.T_{l t},{ }_{F I}\right)$, and $\mathrm{b}$ - the deficit irrigated treatment $\left(T_{\text {daily }{ }^{D I}}\right.$ and $\left.T_{l t},{ }_{D I}\right)$. of $R_{d}$ proposed by Goudriaan and van Laar (1994) in the $A g_{s}$ model increased prediction errors, indicating that the original parameterization for $R_{d}$ could better represent the water stress condition. Modifying the leaf angle distribution $G$ to erectophile as suggested by Roujean (1996) reduced $t_{c}$ prediction errors and increased model efficiency, especially for the deficit irrigated treatment.

The model was shown to be most sensitive to $g_{m}$ and a significant improvement in model performance was obtained by reducing the value of $g_{m, 25}$ to $3.9 \mathrm{~mm} \mathrm{~s}^{-1}$, as suggested by Flowers et al. (2007). We investigated the optimum value for $g_{m, 25}$ and found that $3.9 \mathrm{~mm} \mathrm{~s}^{-1}$ is, in fact, the best value for the fully irrigated treatment $(F I)$. For the deficit irrigated treatment $(D I), g_{m, 25}=4.4 \mathrm{~mm} \mathrm{~s}^{-1}$ gave the best model performance $\left(R M S E P=6.39^{\circ} \mathrm{C}, M E=0.6^{\circ} \mathrm{C}\right.$, $E=0.32$ ). The diffusional limitations to photosynthesis imposed by reductions in mesophyll conductance in water limited environments is not reported to be important to all common bean cultivars (Lizana et al., 2006). However, for the Carioca cultivar used in our study a reduced value of $g_{m, 25}$ better represented the photosynthetic process when plants were water stressed.

The obtained transpiration rates with $g_{m, 25}=3.9 \mathrm{~mm} \mathrm{~s}^{-1}$ for the $F I$ treatment and with $g_{m, 25}=4.4 \mathrm{~mm} \mathrm{~s}^{-1}$ for the $D I$ treatment were plotted against time to correlate the estimated transpiration rate to different environmental-plant variables which control the transpiration process on different time scales (Fig. 2). The temporal trend during the entire growth cycle could be described by a first-degree polynomial equation for the $F I$ treatment $\left(T_{F I}=42.455+\right.$ $3.337 \tau ; \mathrm{R}^{2}=0.22$ ), and by a third-degree polynomial equation for the DI treatment $\left(T_{D I}=34.764+16.175 \tau-1.196\right.$ $\left.t^{2}+0.0232 t^{3} ; \mathrm{R}^{2}=0.13\right)$. Well-watered bean plants of the FI treatment linearly increased transpiration rate, whereas plants under water stress (DI treatment) showed an increasing trend in transpiration rate for some days after irrigation had been suspended but it decreased with time as the soil dried out. This suggests that transpiration was limited by water shortage in the soil and in this case the atmospheric demand for water vapour did not affect the transpiration rate, as discussed by Tuzet et al. (2003) and Medina and Gilbert (2016). By the end of the period, an irrigation gift of $\sim 15 \mathrm{~mm}$ was applied to guarantee plant survival and the trend of transpiration rate was to increase.

Using the trend equations, a detrending was performed on half-hourly transpiration rate data series in daytime to separate it in the long term $\left(T_{l t}\right)$ and daily $\left(T_{d a i l}\right)$ temporal components for both irrigation treatments (Fig. 3). The $T_{l t}$ component was obtained by the fitted polynomial equations and $T_{\text {daily }}$ was given by taking the difference between the $T$ estimates of the $A g_{s}$ model and $T_{l t}$ and adding the minimum values of $T_{l t}: 98.5 \mathrm{mg} \mathrm{m}^{2} \mathrm{~s}^{1}$ for the deficit irrigated treatment, and $126.68 \mathrm{mg} \mathrm{m}^{2} \mathrm{~s}^{1}$ for the fully irrigated treatment. The afternoon depression $\left(T_{d}\right)$, the third temporal component of transpiration data sets, could also be identified in 
a
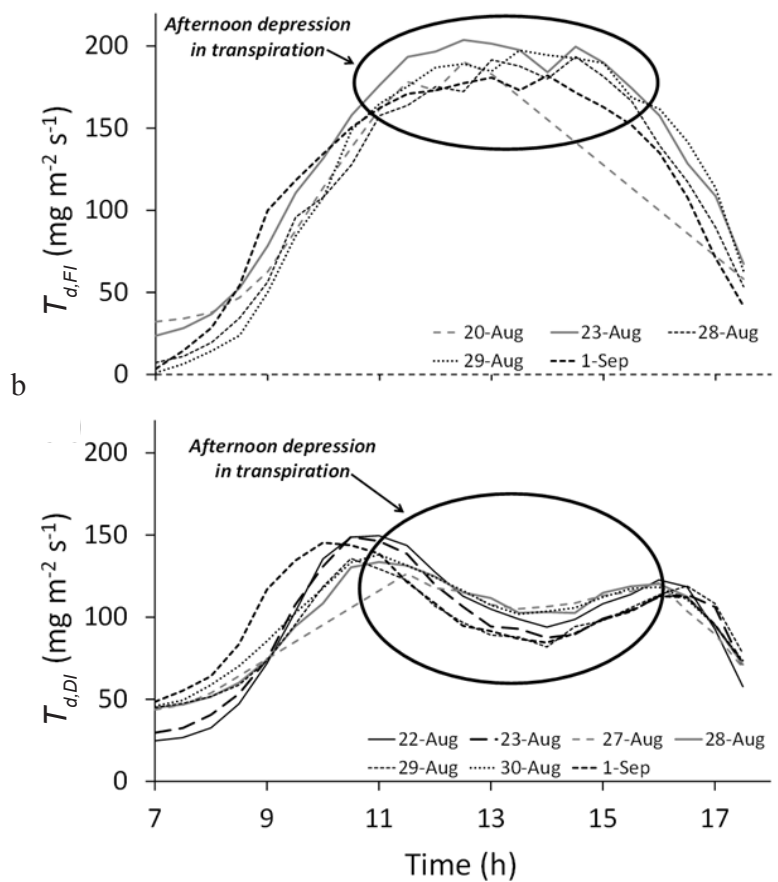

Fig. 4. Afternoon depression $\left(T_{d}, \mathrm{mg} \mathrm{m}^{-2} \mathrm{~s}^{-1}\right)$ component of plant transpiration rate for: a - the fully irrigated treatment $\left(T_{d^{\prime} F}\right)$, and $\mathrm{b}$ - the deficit irrigated treatment $\left(T_{d^{\prime} D I}\right)$.

$T_{\text {daily }}$ data sets (Fig. 4). It shows a noise in transpiration rates between $11 \mathrm{~h}$ and $16 \mathrm{~h}$ on 5 days in the $F I$ treatment and a deep depression in transpiration around this period on 7 days in the DI treatment. As can be seen in Fig. 4, the depression in transpiration of well-watered plants is much less pronounced than the one observed in water stressed plants.

After separating the transpiration data series in three main temporal components $\left(T_{\text {daily }}, T_{l t}\right.$ and $\left.T_{d}\right)$, each one was correlated to environmental and plant forcing variables. Temporal components were analysed using the principal component analysis (PCA) methodology. Prior to PCA, the atmospheric water potential $\psi$ was calculated using Eq. (27) for both irrigation treatments and is presented in Fig. 5 together with the mean soil water pressure head $h_{m}$. While the soil became much drier in the deficit irrigated treatment than in the fully irrigated treatment (minimum $h_{m, 3}$ and $h_{m, 4} \approx-0.49 \mathrm{MPa}$, and minimum $h_{m, 1}$ and $\left.h_{m, 2} \approx-0.03 \mathrm{MPa}\right), \psi$ decreased almost equally in both of them as there was no rainfall for 53 days and the atmospheric potential decreased. Therefore, although plants in the FI treatment grew in a well-watered soil, they were subjected to a very dry atmospheric environment. High vapour pressure deficit in the atmospheric air is reported to decrease stomatal conductance and transpiration rate (Bunce, 1997; Shekoofa et al., 2016) even in a well-watered soil.

The PCA was performed by taking the data series of $T_{\text {daily }}, T_{l t}$ and $T_{d}$ together with selected environmental-plant variables (identified in the following by $E P$ ): specific
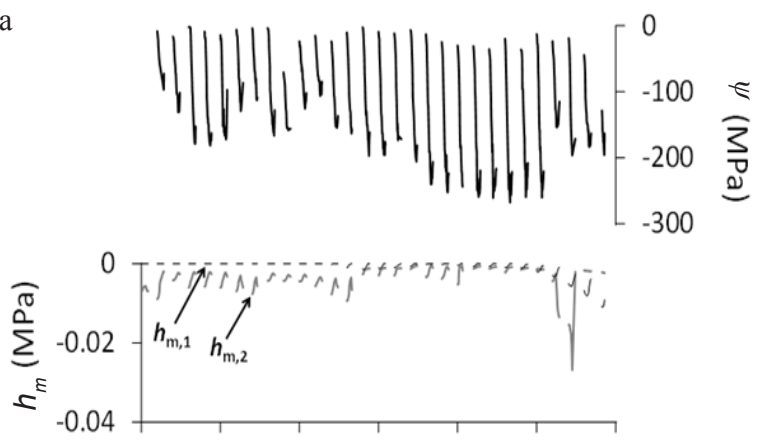

b
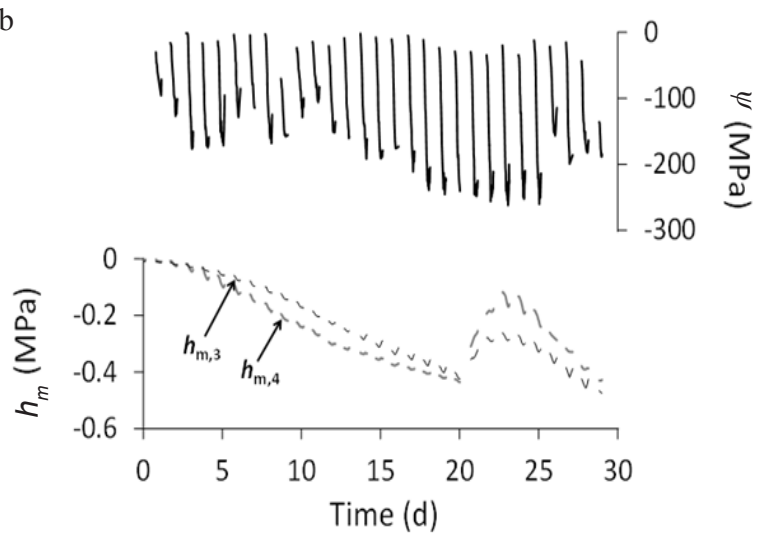

Fig. 5. Mean soil water pressure head $h_{m}(\mathrm{MPa}-$ Eq. (28)) at two observation points and the atmospheric water potential $\psi(\mathrm{MPa})$ observed in: $\mathrm{a}$ - the fully irrigated treatment $(F I)$, and $\mathrm{b}$ - the deficit irrigated treatment $(D I)$.

humidity deficit between leaf and air $\left(D_{s}\right)$, photosynthetically active radiation $\left(I_{P A R}\right)$, relative humidity $\left(H_{R}\right)$, canopy and air temperature $\left(t_{\mathbf{c}}\right.$ and $\left.t_{\text {air }}\right)$, wind speed $(u)$, mean soil water pressure head at two observation points each irrigation treatment $\left(h_{m}\right)$, atmospheric water potential $\psi$, and leaf area index $\left(L_{L A I}\right)$. To characterise the environment which was controlling plant transpiration, PCA was also performed by taking only the selected environmental and plant variables ( $E P$ for $T_{\text {daily }}, T_{l t}$ and $\left.T_{d}\right)$. All accumulated variances of the principal components are presented in Table 4. For both FI and DI treatments the first three principal components accounted for more than $80 \%$ of the variance of the data sets of estimated transpiration rates combined with the data sets of the ten environmental-plant variables (totalling eleven variables). The same was observed when only environmental-plant data sets (ten variables) were analysed. In all cases, the first principal component accounted for more than $50 \%$ of the variance in data sets. In this case, those variables cumulatively accounting for approximately $20 \%$ of total variance can be removed from the data set with a negligible loss of information (Mundlak, 1981). Data of the environmental-plant data sets for $T_{\text {daily }}$ and $T_{l t}$ components are different from those of the $T_{d}$ component as $T_{d}$ represents only some days of the entire $T_{\text {daily }}$ data sets. For this reason, they are presented separately in Tables 4-5 (named as $E P$ for $T_{d a i l y, F I}$ and $T_{l t, F I}, E P$ for $T_{d a i l y, D I}$ and $T_{l t, D I}$, $E P$ for $T_{d, F I}$, and $E P$ for $\left.T_{d, D I}\right)$. 
T a b l e 4. Accumulated variance explained by the principal components related to the daily, long term, and depression transpiration time components and related to the environmental-plant variables (EP) for the fully irrigated treatment $\left(T_{d a i l y},{ }_{F I}, T_{l t, F I}, T_{d, F I}, E P\right.$ for $T_{d a i l y}, F I$ and $T_{l t, F}$, and $E P$ for $\left.T_{d}, F I\right)$, and deficit irrigated treatment $\left(T_{d a i l y},{ }_{D I}, T_{l t},{ }_{D I}, T_{d, D I}, E P\right.$ for $T_{d a i l y}$, ${ }_{D I}$ and $T_{l t}$, ${ }_{D I}$, and $E P$ for $\left.T_{d, D I}\right)$. Variance could be explained by the principal component 1,2 and 3 in both irrigation treatments

\begin{tabular}{|c|c|c|c|c|}
\hline \multirow{3}{*}{ Irrigation treatment } & \multirow{3}{*}{ Components for PCA } & \multicolumn{3}{|c|}{ Accumulated variance $(\%)$} \\
\hline & & \multicolumn{3}{|c|}{ Principal component } \\
\hline & & 1 & 1 and 2 & 1,2 and 3 \\
\hline \multirow{5}{*}{$F I$} & $T_{\text {daily } F I}$ & 54.9 & 70.2 & 82.7 \\
\hline & $T_{l t}, F I$ & 50.1 & 70.3 & 82.6 \\
\hline & $E P$ for $T_{\text {daily, } F I}$ and $T_{l t}, F I$ & 52.8 & 68.5 & 82.0 \\
\hline & $T_{d}{ }_{F I}$ & 57.5 & 75.9 & 88.6 \\
\hline & $E P$ for $T_{d}, F I$ & 54.6 & 74.8 & 87.9 \\
\hline \multirow{5}{*}{$D I$} & $T_{\text {daily }}, D I$ & 54.0 & 74.1 & 84.6 \\
\hline & $T_{l t}, D I$ & 50.8 & 71 & 84.1 \\
\hline & $E P$ for $T_{\text {daily }{ }_{D I}}$ and $T_{l t}{ }^{\prime} D I$ & 54.7 & 74.4 & 85.8 \\
\hline & $T_{d}{ }_{D I}$ & 52.2 & 76.0 & 86.7 \\
\hline & $E P$ for $T_{d},{ }_{D I}$ & 51.8 & 78.0 & 89.0 \\
\hline
\end{tabular}

From the foregoing we find that the transpiration rate data sets and environmental and plant data sets can be represented by three components. The next step is to identify which three variables can best represent these data sets. In Table 5 we present the percentage of variance of each input variable accounted for (final communality) for $F I$ and $D I$ treatments, respectively. Unlike the cumulative proportion, these statistics are related to one input variable at a time and it is possible to detect which input variables are better or worse represented by the reduction of the number of parameters.

For the fully irrigated treatment (Table 5), the specific humidity deficit between stomata and air $\left(D_{s}\right)$, the relative air humidity $\left(H_{R}\right)$ and the canopy temperature $\left(t_{\mathrm{c}}\right)$ are the variables that capture most of the variance on daily and long term temporal components of transpiration and environmental-plant data sets. This is in agreement with Fletcher et al. (2007), who reported close correlation between transpiration rate of well-watered soybean plants and vapour pressure deficit, a variable representing the atmospheric demand to water vapour like $D_{s}$ and $H_{R}$. For the component $T_{d}$, the variance of $H_{R}$ slightly decreased and the third most representative variable was the estimated transpiration rate itself. This is explained by the fact that the afternoon transpiration depression occurs when plants close their stomata (increasing $t_{c}$ ) in response to the high midday atmospheric demand to water vapour (high $D_{s}$ and low $H_{R}$ ) (Leuning, 1995; Hérould et al., 2013). As soil water was not limiting plant growth in this treatment, simulated plant transpiration mainly responded to the atmospheric controlling variables, irrespective of the temporal component.

In the $D I$ treatment (Table 5), the variables representing the variance in the data sets changed in relation to the $F I$ treatment and also between temporal components. Relative air humidity $\left(H_{R}\right)$, canopy temperature $\left(t_{c}\right)$ and mean soil water pressure head at observation point $3\left(h_{m, 3}\right)$ are the most representative variables for the $T_{\text {daily }}$ component, while $t_{c}$ and the mean soil water pressure head at points 3 and $4 \stackrel{c}{(h}{ }_{m, 3}$ and $\left.h_{m, 4}\right)$ describe an important part of the variance in the $T_{\mathrm{lt}}$ component. Although representing a major part of the variance in both data sets $\left(T_{\text {daily }}\right.$ and $\left.T_{l t}\right)$, as water shortage in the soil was limiting transpiration, mean soil water pressure head accounted for a large part of the variance in the $T_{l t}$ component. The environmental-plant data set $(E P)$ also showed a high influence of $H_{R}, t_{c}$ and $h_{m, 3}$ on its main variance. These variables are more related to a plant water stress condition due to a dry atmospheric air, a high sensitive heat load on plants, and a soil water shortage, respectively, which are conditions likely to occur in the deficit irrigated treatment. The $T_{\mathrm{d}}$ data set and the environmental-plant data set could be mainly represented by $H_{R}, t_{c}$ and $h_{m, 4}$. The afternoon depression in transpiration of the DI treatment occurred when plants closed their stomata (increasing $t_{\mathrm{c}}$ ) in a combined response to the high atmospheric demand to water vapour (low $H_{R}$ ) and to the soil water content shortage (very low $h_{m, 4}$ ) (Martínez-Vilalta $e t$ al., 2014). 
T a b l e 5. Final communality (\%) for the variables most related to the principal components for transpiration simulation of the fully and deficit irrigated treatments $\left(E P\right.$ : environmental-plant variables; $D_{s}$ : specific humidity deficit between leaf and air; $I_{P A R}$ : photosynthetically active radiation; $H_{R}$ : relative humidity; $t_{c}$ : canopy temperature; $t_{\text {air }}$ : air temperature; $u$ : wind speed; $h_{m}:$ mean soil water pressure head; $\psi$ : atmospheric water potential; $L_{L A I}:$ leaf area index)

\begin{tabular}{|c|c|c|c|c|c|}
\hline \multirow[t]{2}{*}{ Parameter } & \multicolumn{5}{|c|}{ Final communality (\%) } \\
\hline & $T_{\text {daily } F I}$ & $T_{l t, F I}$ & $\begin{array}{l}E P \text { for } T_{\text {daily, } F I} \\
\quad \text { and } T_{l t, F I}\end{array}$ & $T_{d, F I}$ & $E P$ for $T_{d, F I}$ \\
\hline$T_{\text {daily }}$, or $T_{l t}$, or $T_{d}\left(\mathrm{mg} \mathrm{m}^{-2} \mathrm{~s}^{-1}\right)$ & 91.6 & 92.8 & - & 96.4 & - \\
\hline$D_{s}\left(\mathrm{mg} \mathrm{kg}^{-1}\right)$ & 97.7 & 96.9 & 96.9 & 98.8 & 98.4 \\
\hline$I_{P A R}\left(\mathrm{~W} \mathrm{~m}^{-2}\right)$ & 62.7 & 58.3 & 57.7 & 74.2 & 70.2 \\
\hline$H_{R}(\%)$ & 94.3 & 95.4 & 95.4 & 95.2 & 96.1 \\
\hline$t_{c}\left({ }^{\circ} \mathrm{C}\right)$ & 94.6 & 94.5 & 94.5 & 97.2 & 97.2 \\
\hline$t_{\text {air }}\left({ }^{\circ} \mathrm{C}\right)$ & 88.7 & 89.2 & 89.5 & 94.8 & 95.1 \\
\hline$u\left(\mathrm{~mm} \mathrm{~s}^{-1}\right)$ & 58.8 & 59.7 & 66.0 & 77.5 & 80.0 \\
\hline$h_{m, 1}(\mathrm{MPa})$ & 84.6 & 74.9 & 85.7 & 91.8 & 92.0 \\
\hline$h_{m, 2}(\mathrm{MPa})$ & 63.1 & 63.3 & 63.2 & 66.4 & 67.3 \\
\hline$\psi(\mathrm{MPa})$ & 89.3 & 90.1 & 89.9 & 89.2 & 89.6 \\
\hline \multirow[t]{2}{*}{$L_{L A I}\left(\mathrm{~m}^{2} \mathrm{~m}^{-2}\right)$} & 83.9 & 93.3 & 81.5 & 92.7 & 92.7 \\
\hline & $T_{\text {daily, } D I}$ & $T_{l t, D I}$ & $\begin{array}{l}E P \text { for } T_{\text {daly, } D I} \\
\quad \text { and } T_{l t, D I}\end{array}$ & $T_{d, D I}$ & $E P$ for $T_{d, D I}$ \\
\hline$T_{\text {daily }}$, or $T_{l t}$, or $T_{d}\left(\mathrm{mg} \mathrm{m}^{-2} \mathrm{~s}^{-1}\right)$ & 78.1 & 84.7 & - & 70.1 & - \\
\hline$D_{s}\left(\mathrm{mg} \mathrm{kg}^{-1}\right)$ & 92.7 & 94.4 & 94.6 & 92.6 & 95.2 \\
\hline$I_{P A R}\left(\mathrm{~W} \mathrm{~m}^{-2}\right)$ & 60.0 & 47.9 & 55.3 & 67.5 & 64.0 \\
\hline$H_{R}(\%)$ & 95.6 & 95.3 & 94.9 & 98.2 & 97.3 \\
\hline$t_{c}\left({ }^{\circ} \mathrm{C}\right)$ & 96.6 & 97.2 & 97.2 & 97.5 & 98.3 \\
\hline$t_{a i r}\left({ }^{\circ} \mathrm{C}\right)$ & 91.5 & 90.7 & 92.4 & 94.4 & 94.3 \\
\hline$u\left(\mathrm{~mm} \mathrm{~s}^{-1}\right)$ & 67.0 & 40.4 & 72.4 & 73.3 & 79.6 \\
\hline$h_{m, 3}(\mathrm{MPa})$ & 99.0 & 99.0 & 99.4 & 82.8 & 83.3 \\
\hline$h_{m, 4}(\mathrm{MPa})$ & 90.7 & 98.0 & 90.9 & 99.6 & 99.6 \\
\hline$\psi(\mathrm{MPa})$ & 88.4 & 86.3 & 89.4 & 95.0 & 94.8 \\
\hline$L_{L A I}\left(\mathrm{~m}^{2} \mathrm{~m}^{-2}\right)$ & 70.9 & 91.5 & 71.9 & 82.5 & 84.1 \\
\hline
\end{tabular}

\section{CONCLUSIONS}

1. Using the parameterizations recovered in the $A g_{s}$ model and simulating plant transpiration rate resulted in a moderate reduction of prediction errors and in an increase in model performance. The model was shown to be the most sensitive to changes in the mesophyll conductance parameterization, and special attention should be given to the parameterization for the leaf angle distribution when transpiration of plants under water stress is estimated. The use of an erectophile function for leaf angle distribution, better representing leaf distribution under water stress, also improved model performance.

2. Transpiration data sets simulated with a new parameterization for mesophyll conductance could be separated in the temporal components which were well related to the main forcing variables controlling plant transpiration for each environmental and soil water condition. The daily, the 
afternoondepressionand the long term transpiration temporal components of the fully irrigated treatment were more related to the atmospheric forcing variables which were causing a high transpiration rate due to the dry atmospheric air (stomata-air specific humidity deficit, relative air humidity and canopy temperature). The daily and afternoon depression transpiration temporal components of the deficit irrigated treatment were related to both the atmospheric and soil dryness, whereas the long term transpiration component of this treatment mostly responded to soil water shortage. These qualitative relations were determined by applying the principal component analysis methodology.

3. The modified versions of the $A g_{s}$ model by Jacobs (1994) were able to simulate plant transpiration and its three temporal components in very dry conditions. Without using soil data as a model input, consistent values of transpiration in a temporal component closely related to soil water availability (long term) were simulated by a parameterization representative of the water deficit condition. These results show the ability of the $A g_{s}$ model to simulate plant transpiration under dry conditions without using specific soil input data, thus avoiding the need to obtain soil data and to consider the naturally occurring soil heterogeneity.

Conflict of interest: The Authors do not declare conflict of interest.

\section{REFERENCES}

Abdi H. and Williams L.J., 2010. Principal component analysis. Wiley Interdiscip. Rev. Comput. Stat., 2, 433-459.

Albergel C., Calvet J.-C., Gibelin A.-L., Lafont S., Roujean J.-L., Berne C., Traullé O., and Fritz N., 2010. Observed and modelled gross primary production and ecosystem respiration of a grassland in southwestern France. Biogeosciences, 7, 1657-1668.

Allen R.G., Pereira L., and Raes D., 1998. Crop Evapotranspiration. FAO Irrigation and Drainage Paper 56, FAO, Rome, Italy.

Amthor J.S., 1995. Predicting effects of atmospheric $\mathrm{CO}_{2}$ partial pressure on forest photosynthesis. J. Biogeography, 22, 269-280.

Ansley R.J., Dugas W.A., Heuer M., and Trevino B., 1994. Stem flow and porometer measurements of transpiration from honey mesquite (Prosopis glandulosa). J. Exp. Bot., 45(275), 847-856.

Archontoulis S.V., Vos J., Yin X., Bastiaans L., Danalatos N.G., and Struik P.C., 2011. Temporal dynamics of light and nitrogen distributions in canopies of sunflower, kenaf and cynara. Field Crop. Res., 122, 186-198.

Atti S., Bonnel R., Prasher S., and Smith D.L., 2005. Response of soybean \{Glycine $\max (\mathrm{L}$.) merr.\} under chronic water deficit to LCO application during flowering and pod filling. Irrig. Drain., 54, 15-30.

Bakker G., Van der Ploeg M.J., De Rooij G., Hoogendam C.W., Gooren H.P., Huiskes C., Koopal L.K., and Kruidhof H., 2007. New polymer tensiometers: measuring matric pressures down to the wilting point. Vadose Zone J., 6, 196-202.
Ballantyne A.P., Miller J.B., Baker I., Tans P.P., and White J., 2011. Novel applications of carbon isotopes in atmospheric $\mathrm{CO}_{2}$ : what can atmospheric measurements teach us about processes in the biosphere? Biogeosciences, 8, 3093-3106.

Bonan G.B., Lawrence P.J., Oleson K., Levis S., Jung M., Reichstein M., Lawrence D., and Swenson S., 2011. Improving canopy processes in the Community Land Model version 4 (CLM4) using global flux fields empirically inferred from FLUXNET data. J. Geophys. Res., 116, G02014, doi:10.1029/2010JG001593

Boussetta S., Balsamo G., Beljaars A., Agusti-Panareda A., Calvet J.-C., Jacobs C., Van den Hurk B., Viterbo P., Lafont S., Dutra E., Jarlan L., Balzarolo M., Papale D., and Van der Werf G., 2013. Natural land carbon dioxide exchanges in the ECMWF Integrated Forecasting System: Implementation and offline validation. J. Geophys. Res. D: Atmos., 118, 5923-5946.

Bunce J.A., 1997. Does transpiration control stomatal responses to water vapour pressure deficit? Plant, Cell Environ., 20, 131-135.

Calvet J.-C., Noilhan J., Roujean J.-L., Bessemoulin P., Cabelguenne M., Olioso A., and Wigneron J.-P., 1998. An interactive vegetation SVAT model tested against data from six contrasting sites. Agric. For. Meteorol., 92, 73-95.

Cowan I., 1982. Regulation of water use in relation to carbon gain in higher plants. In: Physiological Plant Ecology II. Water Relations and Carbon Assimilation (Eds O.E. Lange, P.S. Nobel, C.B. Osmond, H. Ziegler). Springer-Verlag, Berlin, Germany.

De Lorenzi F. and Rana G., 2000. Sap flow transportation measurements in a table grape vineyard growing in Southern Italy. Acta Hortic., 537, 69-75.

Dugas W.A., Wallace J., Allen S., and Roberts J., 1993. Heat balance, porometer, and deuterium estimates of transpiration from potted trees. Agric. For. Meteorol., 64, 47-62.

Durigon A., 2011. Soil-plant-atmosphere water transfer mechanisms and their relation to crop water stress. Ph.D. Thesis - University of São Paulo, Piracicaba, Brazil.

Durigon A., Santos M., De Jong van Lier Q., and Metselaar K., 2012. Pressure heads and simulated water uptake patterns for a severely stressed bean crop. Vadose Zone J., 11(3), doi:10.2136/vzj2011.0187

Escalona J.M., Flexas J., and Medrano H., 1999. Stomatal and non-stomatal limitations of photosynthesis under water stress in field-grown grapevines. Aust. J. Plant Physiol., 26, 421-433.

Escalona L., Flexas J., and Medrano H., 2000. Comparison of heat balance and gas exchange methods to measure transpiration in irrigated and water stressed grapevines. Acta Hortic., 526, 145-156.

Farquhar G.D., Von Caemmerer S., and Berry J., 1980. A biochemical model of photosynthetic $\mathrm{CO}_{2}$ assimilation in leaves of $\mathrm{C}_{3}$ species. Planta, 149, 78-90.

Fletcher A.L., Sinclair T.R., and Allen L., 2007. Transpiration responses to vapor pressure deficit in well watered 'slowwilting' and commercial soybean. Environ. Exp. Bot., 61, 145-151.

Flexas J., Ribas-Carbo M., Bota J., Galmés J., Henkle M., Martínez-Cañellas S., and Medrano H., 2006. Decreased Rubisco activity during water stress is not induced by decreased relative water content but related to conditions of low stomatal conductance and chloroplast $\mathrm{CO}_{2}$ concentration. New Phytol., 172, 73-82. 
Flexas J., Ribas-Carbo M., Diaz-Espejo A., Galmés J., and Medrano H., 2008. Mesophyll conductance to $\mathrm{CO}_{2}$ : current knowledge and future prospects. Plant, Cell and Env., 31, 602-621.

Flowers M.D., Fiscus E., Burkey K., Booker F.L., and Dubois J.-J., 2007. Photosynthesis, chlorophyll fluorescence, and yield of snap bean (Phaseolus vulgaris L.) genotypes differing in sensitivity to ozone. Environ. Exp. Bot., 61, 190-198.

Galle A., Florez-Sarasa I., Tomas M., Pou A., Medrano H., Ribas-Carbo M., and Flexas J., 2009. The role of mesophyll conductance during water stress and recovery in tobacco (Nicotina sylvestris): acclimation or limitation? J. Exp. Bot., 60, 2379-2390.

Galmés J., Ribas-Carbo M., Medrano H., and Flexas J., 2007. Response of leaf respiration to water stress in Mediterranean species with different growth forms. J. Arid Environ., 68, 206-222.

Ganann R., Ciliska D., and Thomas H., 2010. Expediting systematic reviews: methods and implications of rapid reviews. Implement. Sci., 5, 56, doi 10.1186/1748-5908-5-56

Goudriaan J. and Van Laar H., 1994. Modelling Potential Crop Growth Processes. Kluwer Academic Publishers, Dordrecht, The Netherlands.

Goudriaan J., Van Laar H., Van Keulen H., and Louwerse W., 1985. Photosynthesis, $\mathrm{CO}_{2}$ and Plant Production. In: Wheat Growth and Modeling (Eds W. Day, R.K. Atkin). Plenum Press, New York, USA.

Guimarães C.M., Brunini O., and Stone L.F., 1993. Differential root density and water extraction rate of bean (Phaseolus vulgaris L.) drought-sensitive and tolerant cultivars. Annual Report of the Bean Improvement Cooperative, 36, 78-79.

Héroult A., Lin Y.S., Bourne A., Medlyn B.E., and Ellsworth D.S., 2013. Optimal stomatal conductance in relation to photosynthesis in climatically contrasting Eucalyptus species under drought. Plant Cell Environ., 36, 262-274.

Hommel R., Siegwolf R., Zavadlav S., Arend M., Schaub M., Galiano L., Haeni M., Kayler Z.E., and Gessler A., 2016. Impact of interspecific competition and drought on the allocation of new assimilates in tress. Plant Biology, doi:10.1111/plb.12461

Jacobs C.M.J., 1994. Direct impact of atmospheric $\mathrm{CO}_{2}$ enrichment on regional transpiration. Ph.D. Thesis, Agricultural University, Wageningen, The Netherlands.

Jacobs C.M.J., Van den Hurk B.M., and De Bruin H.A., 1996. Stomatal behavior and photosynthetic rate of unstressed grapevines in semi-arid conditions. Agric. For. Meteorol., 80(2), 111-134.

Jones H.G., 2004. Application of thermal imaging and infrared sensing in plant physiology and ecophysiology. Adv. Bot. Res., 41(1), 107-163.

Leuning R., 1995. A critical appraisal of a combined stomatalphotosynthesis model for $\mathrm{C}_{3}$ plants. Plant Cell Environ., 18(2), 339-355.

Lipiec J., Doussan C., Nosalewicz A., and Kondracka K., 2013. Effect of drought and heat stresses on plant growth and yield: a review. Int. Agrophys., 27, 463-477.

Lizana C., Wentworth M., Martinez J.P., Villegas D., Meneses R., Murchie E.H., Pastenes C., Lercari B., Vernieri P., Horton P., and Pinto M., 2006. Differential adaptation of two varieties of common bean to abiotic stress I. Effects of drought on yield and photosynthesis. J. Exp. Botany, 57, 685-697.
Martínez-Vilalta J., Poyatos R., Aguadé D., Retana J., and Mencuccini M., 2014. A new look at water transport regulation in plants. New Phytologist, 204, 105-115.

Medina V. and Gilbert E., 2016. Physiological trade-offs of stomatal closure under high evaporative gradients in field grown soybean. Functional Plant Biology, 43, 40-51.

Moran M.S., Scott R., Keefer T., Emmerich W.E., Hernandez M., Nearing G., Paige G.B., Cosh M., and O'Neil P.E., 2009. Partitioning evapotranspiration in semiarid grassland and shrubland ecosystems using time series of soil surface temperature. Agric. For. Meteorol., 149, 59-72.

Mundlak Y., 1981. On the concept of non-significant functions and its implications for regression analysis. J. Econometrics, 16(1), 139-149.

Nash J.E. and Sutcliffe J., 1970. River flow forecasting through conceptual models, I. A discussion of principles. J. Hydrol., 10, 282-290.

Nobel P.S., 1991. Physiochemical and Environmental Plant Physiology. Academic Press, San Diego, USA.

Olioso A., Inoue Y., Ortega-Farias S., Demarty J., Wigneron J-P., Braud I., Jacob F., Lecharpentier P., Ottlé C., Calvet J.-C., and Brisson N., 2005. Future directions for advanced evapotranspiration modeling: assimilation of remote sensing data into crop simulation models and SVAT models. Irrigation Drainage Systems, 19, 377-412.

Ribas-Carbo M., Taylor N., Giles L., Busquets S., Finnegan P.M., Day D.A., Lambers H., Medrano H., Berry J., and Flexas J., 2005. Effects of water stress on respiration in soybean leaves. Plant Physiol., 139, 466-473.

Roujean J.-L., 1996. A tractable physical model of shortwave radiation interception by vegetative canopies. J. Geophys. Res. D: Atmos., 101(5), 9523-9532.

Shekoofa A., Sinclair T.R., Messina C., and Cooper M., 2016. Variation among maize hybrids in response to high vapor pressure deficit at high temperature. Crop Science, 56, 392-396.

Silva B., Strobl S., Beck E., and Nendix J., 2016. Canopy evapotranspiration, leaf transpiration and water use efficiency of an andrean pasture in SE-Ecuador - a case study. ERDKUNDE, 70, 5-18.

Smolander H. and Lappi J., 1984. The interactive effect of water stress and temperature on the $\mathrm{CO} 2$ response of photosynthesis in Salix. Silva Fennica, 18, 133-139.

Srikanta Dani K.G., Jamie I.M., Colin Prentice I., and Atwell B.J., 2015. Species-specific photorespiratory rate, drought tolerance and isoprene emission rate in plants. Plant Signaling Behavior, 10, 3, doi 10.4161/15592324.2014.990830

Supit I., van Diepen C.A., de Wit A.J.W., Wolf J., Kabata P., Baruth B., and Ludwig F., 2012. Assessing climate change effects on European crop yields using the Crop Growth Monitoring System and a weather generator. Agric. For. Meteorol., 164, 96-111.

Tezara W., Mitchell V., Driscoll S.D., and Lawlor D., 1999. Water stress inhibits plant photosynthesis by decreasing coupling factor and ATP. Nature, 401, 914-917.

Tuzet A., Perrier A., and Leuning R., 2003. A coupled model of stomatal conductance, photosynthesis and transpiration. Plant Cell Environ., 26, 1097-1116.

Van Dam J.C., Groenendijk P., Hendriks R.F., and Kroes J.G., 2008. Advances of modeling water flow in variably saturated soils with SWAP. Vadose Zone J., 7, 640-653. 
Van der Ploeg M.J., Gooren H.P., Bakker G., and De Rooij G., 2008. Matric potential measurements by polymer tensiometers in cropped lysimeters under water-stressed conditions. Vadose Zone J., 7, 1048-1054.

Warren C.R., 2008. Stand aside stomata, another actor deserves centre stage: the forgotten role of the internal conductance to $\mathrm{CO}_{2}$ transfer. J. Exp. Bot., 59, 1475-1487.
Wang Y.P., Yu Q., Li J., Li L.-H., Li X.-G., Yu G.-R., and Sun X.-M., 2006. Simulation of diurnal variations of $\mathrm{CO}_{2}$, water and heat fluxes over winter wheat with a model coupled photosynthesis and transpiration. Agric. For. Meteorol., 137, 194-219.

Zagdańska B., 1995. Respiratory energy demand for protein turnover and ion transport in wheat leaves upon water demand. Physiol. Plant., 95, 428-436. 